\title{
Review
}

Intervirology

\section{Resistance of Enteric Viruses on Fomites}

\author{
Enagnon Kazali Alidjinou Famara Sane Swan Firquet \\ Pierre-Emmanuel Lobert Didier Hober
}

Laboratoire de Virologie EA3610, CHU de Lille, Faculté de Médecine, Université de Lille, Lille, France

\section{Keywords}

Enteric viruses · Survival · Environment · Fomites ·

Inactivation

\begin{abstract}
Human enteric viruses are associated with several clinical features, especially gastroenteritis. Large amounts of these viruses can be released in the environment and spread to people. Enteric viruses are nonenveloped viruses and have displayed good survival in the environment. They can be significantly resistant in food and water but also on fomites, and this is thought to play a role in transmission, leading to sporadic cases or outbreaks. The survival of enteric viruses on fomites relies on many factors including the virus itself, fomite properties, and extrinsic environmental factors such as temperature or relative humidity. Several reports in the literature have found an association with gastroenteritis cases or outbreaks and fomites naturally contaminated by enteric viruses. However, the study of virus survival following natural contamination is challenging, and most published studies are laboratory based, using experimental contamination. In addition, recent and detailed data on the resistance of each of the main enteric viruses on fomites are scarce. Many approaches, both physical and chemical, can be used to inactivate enteric viruses, the efficacy of which depends on the virus and the disinfection conditions.

(c) 2017 S. Karger AG, Basel
\end{abstract}

\section{Introduction}

The term "enteric viruses" refers to an important but complex community of viruses found in the intestinal tract of humans and animals. Enteric viruses include more than 100 viral entities belonging to families such as Reoviridae, Caliciviridae, Astroviridae, Adenoviridae, and Picornaviridae and more rarely Coronaviridae and Picobirnaviridae. These agents are related to a broad range of clinical features including gastroenteritis mainly but also hepatitis, neurological manifestations, and others. The main representatives in humans are rotavirus, norovirus, astrovirus, adenovirus, enterovirus, hepatitis A virus (HAV), and hepatitis E virus (HEV) [1-3].

Individuals infected with enteric viruses can excrete large amounts of viral particles in body secretions, especially feces, even beyond the stage of symptomatic illness. These nonenveloped viruses are very stable in the environment and they are transmitted via the fecal-oral route. Most outbreaks of enteric viral disease have been associated with water- or foodborne transmission $[4,5]$.

However, contamination of environmental surfaces seems to play an important role in the spread of these infections, especially in indoor establishments such as hospitals, nurseries, day care centers, and institutions for the elderly. Many enteric viruses have been associated with nosocomial and health care-related infections via con-

\section{KARGER}

(c) 2017 S. Karger AG, Basel 
Fig. 1. Interaction between determinants of enteric virus survival on fomites.

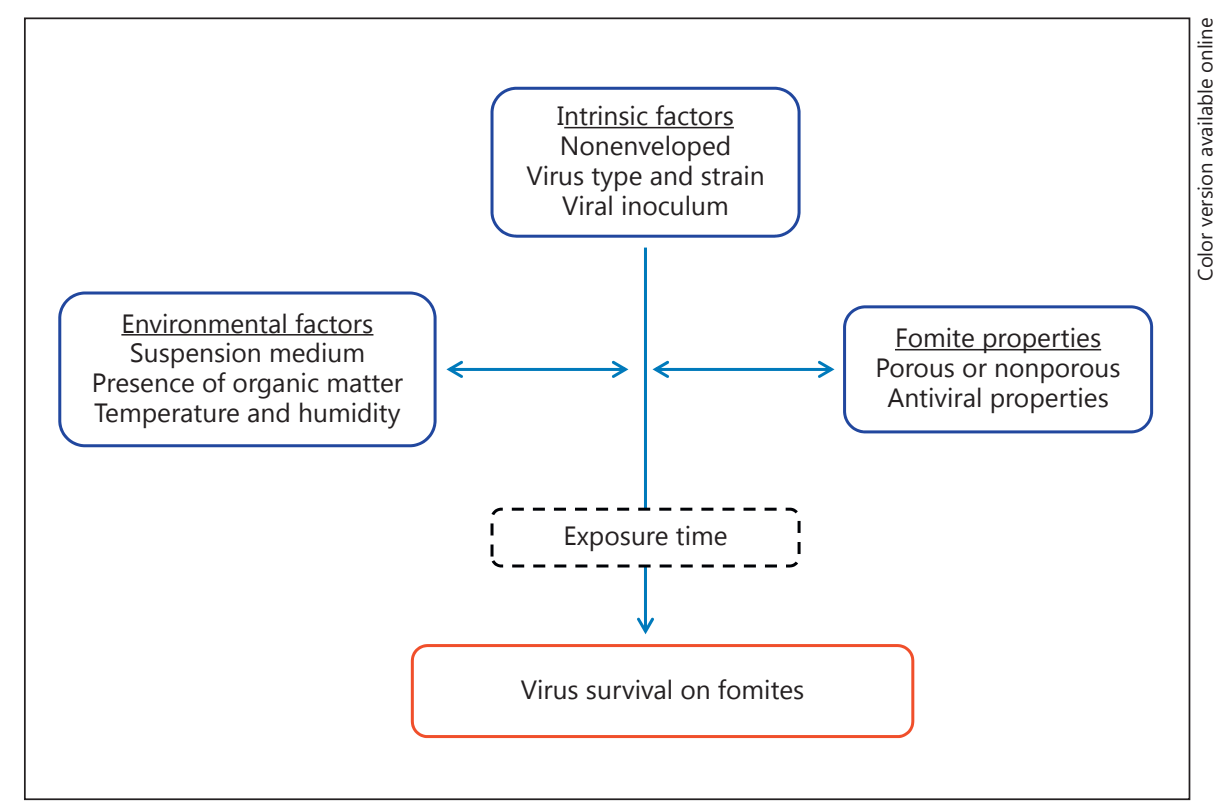

taminated hands and surfaces [6]. Various surfaces such as door handles, clothes, telephones, toilet seats, walls, thermometers, gloves, and papers can be contaminated and serve as vehicles for the virus [7].

Most fomite contaminations occur through direct contact or deposition of aerosol particles containing the virus. Aerosols can be produced for example by toilet flushing [8] or via vomiting, coughing, sneezing, or talking [7]. Thereafter, the virus can be transferred easily to others fomites through interaction with individuals [7].

Virus transfer from hands to fomites and vice-versa is thought to play a significant role in the spreading of infection. It has been shown that hands can be easily contaminated with norovirus by transfer from fomites, and then the contaminated hands could cross-contaminate up to 7 other surfaces without any recontamination [9].

In hospitals and others health care centers, further dissemination has been associated with parents and staff trafficking when hygiene measures such as hand washing before and after visiting a patient are not strictly respected [10].

The prevention of enteric virus-related nosocomial infections or outbreaks requires a good understanding of virus persistence in the environment and of the role of contaminated surfaces and objects in virus transmission.

The survival of main enteric viruses on fomites and its implication for virus transmission will be analyzed, and the major disinfection procedures and their impact will be described.

\section{Factors Involved in Virus Survival on Fomites}

The resistance of viruses in the environment, which determines the risk of transmission, is multifactorial, depending not only on virus characteristics but also on fomite properties and extrinsic environmental factors (Fig. 1).

The virus type is determinant for survival on surfaces, as well as the initial inoculum. Generally enteric viruses are resistant and have been reported to persist on fomites for several weeks to months, as compared for example to respiratory viruses which can only resist for a few hours or days [11]. The higher the contaminating viral titer is, the longer the persistence will be [7]. Some differences between the groups of viruses involved in gastroenteritis have also been described. HAV and rotavirus have been shown to be more resistant than adenovirus and enterovirus [12].

The nature of fomites could influence the survival of viruses. Surfaces are generally classified as porous (e.g., papers and clothes) or nonporous (e.g., stainless steel, plastic, and glass). Available data suggest that the majority of viruses persist longer on nonporous surfaces [7]; however, results are sometimes conflicting, and the effect of fomite properties might also depend on the viral type. For example, rotavirus seem to survive very well on nonporous surfaces, while results are very variable for porous ones [13]. Poliovirus has been shown to be particularly susceptible to aluminum. By comparing HAV and rota- 
virus, it has been shown that HAV is more resistant on nonporous materials, while rotavirus is more stable on porous surfaces such as paper [12]. In similar conditions, astroviruses are able to persist for up to 90 days on paper, while they survive for a maximum of 60 days on nonporous surfaces [14].

The environmental factors include mainly air temperature and humidity, but the length of virus viability may also depend on the cleanliness of the surface, which can be determined for example by the presence or not of fecal material or by the number of microbes on the surface. These factors largely affect the resistance to desiccation, which appears to be an important determinant of virus survival on fomites [5]. For most enteric viruses, low temperatures have been reported to promote a longer persistence [11]. The effect of humidity is less consistent. It has been reported that decreases in humidity could affect the infectivity of HAV, rotavirus, and adenovirus [12]. Another study found that HAV was further preserved at a low humidity [15]. Conflicting results have also been described for other enteric viruses [11]. Indeed, it has been suggested that viruses have a better survival at both low and high humidity, while intermediate humidity (e.g., between 40 and 70\%) is deleterious [16]. Overall, the humidity level is thought to play an important role in virus persistence in the environment, and it has been suggested to explain the seasonality of rotavirus infections, for example [17]. Nevertheless, in most studies, relative humidity (temperature dependent) has been reported, while some authors have shown more recently that absolute humidity (temperature independent) rather than relative humidity could explain the seasonality of infections [18]. Absolute humidity shows a high correlation between indoor and outdoor conditions [19], and it could be more useful to explain infections occurring in closed environments, such as norovirus outbreaks [18].

\section{Evidence of the Role of Fomites in the Transmission of Enteric Viruses}

The contamination and the survival of enteric viruses on surfaces and objects can undoubtedly explain a significant proportion of acute viral diarrhea. Direct evidence of virus transmission via fomites is difficult to obtain because others routes such as person-to-person transmission are also usually suspected.

Enteric viruses have been detected frequently from naturally contaminated fomites in hospitals, houses, or others community facilities. The early reported preva-

Resistance of Enteric Viruses on Fomites lence of rotaviruses on fomites was very high, especially in pediatric settings, ranging from 19 to $79 \%$ [20-23]. In a more recent study, a significant rate (14\%) was detected on environmental surfaces in a hospital intensive care unit [24]. Toys were associated with a rotavirus outbreak in a pediatric oncology unit [25]. Beyond detection of viral RNA by RT-PCR, infectious particles have been reported in some cases [24]. Noroviruses have been found on surfaces and objects around patients during outbreaks in hospitals, hotels, or cruise ships $[7,26,27]$. The role of contamination of environmental surfaces such as dining room tables or elevator buttons used by staff has been reported in a norovirus outbreak in a long-term care center [28]. Touching a reusable grocery bag was linked to cases in a norovirus outbreak in a soccer team [29]. A high rate of norovirus contamination (58\%) in environmental swabs has been observed during outbreaks [30].

Contamination of fomites by adenoviruses has been described [31,32], including the presence of infectious particles [33].

Detection of astroviruses on environment surfaces was also reported during a hospital outbreak [23, 34]. Contamination of drinking glasses with HAV by a barman during incubation of the infection resulted in an outbreak of hepatitis A in a public house [35].

\section{Experimental Study of Virus Survival on Fomites}

The abundant data available in the literature on virus survival come mainly from laboratory investigations and disinfection intervention studies. All of these studies are generally conducted following similar principles. Briefly, a sample of a specific virus suspension with a known infectious titer is applied on the surface under selected conditions and exposition times that are close to the studied natural contamination. Then, after recovery, the viral titer is determined and compared to the former one, and statistical methods are used to calculate the decline in infectious particles [5]. The recovery method, especially the swab material used (cotton, polyester, rayon, macrofoam, or an antistatic wipe), can be critical for the results [36, 37].

Cell culture methods (plaque assay, 50\% tissue culture infective dose) are required for assessment of the viral titer. Indeed, viral nucleic acids detected by molecular methods cannot differentiate between infective and noninfective viruses. This could constitute a limit to virus survival investigation because only viruses able to propagate in cell lines can be studied. Recently, some authors sug- 
gested new PCR-based approaches that could correlate to viral infectivity either by assessing the presence of an intact genome or an amplifiable undamaged genome using direct amplification or by coupling a pre-PCR sample enzymatic treatment in order to assess viral capsid integrity prior to nucleic acid extraction and amplification [38].

Results are usually expressed as inactivation coefficients defined as the ratio between the decline of the viral titer and time. Alternative ways of expressing viral resistance include T90 and T99 values, which represent the time needed for the initial viral titer to decrease by 90 and $99 \%$, respectively, and they are determined using a survival curve [7].

In the following section, the experimental data accumulated in the literature about the survival of the main enteric viruses on fomites are presented.

\section{Norovirus}

Norovirus is a leading cause of sporadic and epidemic cases of acute gastroenteritis across all age groups worldwide [39]. The virus is highly infectious and $10-100$ virions are enough to cause gastroenteritis. To date, human norovirus cannot be propagated in mammalian cell lines. Therefore, survival and inactivation studies are commonly conducted using cultivable surrogates such as feline calicivirus (FCV) or murine norovirus (MNV) [40]. Doultree et al. [41] assessed FCV survival on glass and glass coverslips. The virus remained infectious for up to 57 days at $4^{\circ} \mathrm{C}$ and the resistance decreased significantly with higher temperatures. D'Souza et al. [42] also found that FCV survived for more than 7 days at room temperature on stainless steel, ceramic, and formica surfaces. A shorter survival ranging from $8-12 \mathrm{~h}$ (keyboard keys and brass) to 2-3 days (telephone buttons and telephone receivers) was reported on uncommon fomites. Unlike norovirus, which is an enteric pathogen, FCV causes respiratory diseases in cats and is not an ideal surrogate. MNV has been reported to be more applicable as a norovirus surrogate because it shows environmental stability and is genetically close to human norovirus [43]. Kim et al. [40] investigated MNV survival on steel and wood, and a better resistance was shown on wood at lower temperature and higher relative humidity values. In another study conducted at room temperature, the authors demonstrated that MNV could survive for up to 28 days on 6 different surfaces and the rank order of infectivity reduction from highest to lowest was stainless steel, plastic, rubber, glass, ceramic, and wood [44]. Human norovirus, MNV, and FCV were found to remain infective beyond 70 days on stainless steel and plastic both at $7^{\circ} \mathrm{C}$ and at room temperature [45].

\section{Rotavirus}

Rotavirus is the leading cause of diarrhea-related illness worldwide among children aged $<5$ years, accounting for the majority of diarrhea-related deaths, especially in low-income countries [46]. Rotavirus has displayed a good resistance in the environment. When rotavirus suspension in culture medium is applied on aluminum and paper, infectious particles can be detected for more than 2 months between 4 and $20^{\circ} \mathrm{C}$ at a high relative humidity. However, in a $20 \%$ fecal suspension, survival was better at $20^{\circ} \mathrm{C}[12]$. The impact of relative humidity is not consistent throughout studies $[13,17]$.

\section{Adenovirus}

Human adenoviruses type 40/41, known as enteric adenoviruses, have been associated with sporadic acute diarrhea as well as outbreaks [47, 48]. Adenovirus 40 has been shown to resist for more than 1 month between 4 and $20^{\circ} \mathrm{C}$. Survival is longer on paper than on aluminum [12].

\section{Astroviruses}

Human astroviruses are considered gastrointestinal pathogens that affect mainly children worldwide [49]. The experimental survival of astroviruses has been poorly investigated. It has been shown that the virus can survive for a long time on both porous and nonporous surfaces. Resistance is better at low temperatures and on porous surfaces (up to 90 days at $4^{\circ} \mathrm{C}$ on paper) [14].

\section{Hepatitis A}

Viral hepatitis A is a global health problem that affects hundreds of millions of children and adults, especially in low-income countries where food and water hygiene may be of a low standard [50]. The virus is primarily a human pathogen transmitted by person-to-person contact or ingestion of contaminated food or water, but contaminated fomites can play a role in transmission. HAV can survive for more than 2 months on fomites, and a better resistance has been observed on nonporous surfaces. Fecal suspension and a low temperature have been shown to have a positive effect on persistence [12], but the impact of the relative humidity level has not been confirmed [15]. A recent study found in similar conditions a better survival on wood [40].

\section{Enteroviruses}

The genus Enterovirus includes a great variety of human pathogens such as polioviruses, coxsackieviruses $\mathrm{A}$ and B, echovirus, and EV71. Enteroviruses can cause gas- 
Table 1. Selected examples of survival of enteric viruses on experimentally contaminated fomites

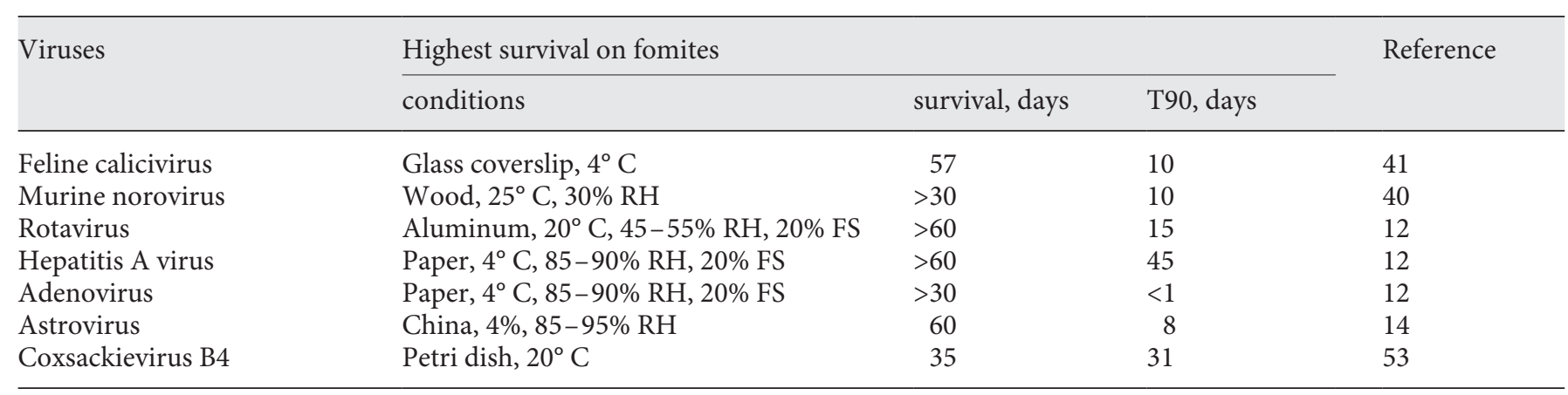

RH, relative humidity; FS, fecal suspension; T90, time needed for the initial viral titer to decrease by $90 \%$.

trointestinal symptoms; however, studies investigating the role of nonpolio enteroviruses in acute diarrhea are rare compared to those on major agents such as rotavirus [51]. Enteroviruses are involved in various and numerous acute diseases, and their role in chronic cardiac diseases and type 1 diabetes is highly suspected [52]. Data on the survival of enteroviruses are scarce, with only few old data focusing on the poliovirus prototype. Poliovirus can survive for up to 1 month at $4^{\circ} \mathrm{C}$. Feces increase survival, while a rapid decrease has been observed on aluminum surfaces [12]. Recently our team investigated the survival of Coxsackievirus B4 on an inanimate surface. When the virus was dried on a petri dish lid at $20^{\circ} \mathrm{C}$, infectious particles could be detected for up to 5 weeks. CVB4 was especially susceptible to repetitive cycles of drying and resuspension, with a significant decrease in the viral titer at each cycle. The viability of CVB4 was also highly reduced when the virus was dried in a protein-rich medium [53].

Selected data on the survival of enteric viruses are shown in Table $1[12,14,40,41,53]$.

\section{Inactivation of Enteric Viruses on Fomites: Physical Approaches}

Several physical inactivation methods have been described for enteric viruses, including heating, high-pressure processing, dehydration, freezing, ultraviolet (UV) inactivation, and heavy metal use. However, some of these approaches cannot be easily applied routinely to surfaces and are more appropriate for water or food. This section only focuses on the methods that can be applied on fomites to reduce virus survival.

Resistance of Enteric Viruses on Fomites

\section{Thermal Inactivation}

Temperature is one of the major factors determining virus survival outside a cell. Its effect on virus inactivation has been evaluated under different conditions, including wet and dry. The common mechanism reported for picornaviruses and caliciviruses is destabilization and disruption of the viral capsid leading to its breakdown and the release of viral RNA [54], while for rotaviruses heat treatment has been shown to primarily target viral transcription functions [55].

Experiments for evaluation of the long-term persistence of enteric viruses outside a cell have shown that, overall, enteric viruses have a long-term survival in suspension at environmental temperatures (e.g., up to $25^{\circ} \mathrm{C}$ ) [56-58].

Thermal inactivation is principally used for enteric viruses in suspension and in food samples and less often for fomites. Two temperatures have been commonly applied: $63^{\circ} \mathrm{C}$, recommended for pasteurization and, $72^{\circ} \mathrm{C}$, recommended for sterilization, with an exposure time of 30 and $2 \mathrm{~min}$, respectively. Under experimental conditions these two temperatures would most likely result in efficient virus inactivation.

Resistance on warmed surfaces of MNV and CVB4 contained in droplets has been studied [59]. CVB4 was inactivated in $5 \mathrm{~s}$ at $70^{\circ} \mathrm{C}$, while $90 \mathrm{~min}$ were necessary to inactivate $\mathrm{MNV}$ at $80^{\circ} \mathrm{C}$.

\section{UV Inactivation}

UV irradiations are commonly used for viral inactivation in food, in water, on food preparation surfaces, and in microbiology laboratories [60,61]. UV-C radiation at wavelengths of 250-280 $\mathrm{nm}$ has been approved for disinfection purposes by the US Food and Drug Administra- 
tion (FDA). Its antiviral activity is well known and can be applied to food, water, and surfaces [60, 62].

Susceptibility may vary between viruses. Enteroviruses have been inactivated with commonly recommended UV-C doses, while adenoviruses have been reported to be more resistant $[63,64]$.

Park and al. [62] evaluated the effect of continuous UV-C treatment on stainless steel experimentally contaminated with MNV and HAV. Their data showed that $\mathrm{HAV}$ was more resistant to UV-C radiation than to MNV. Using various UV-C dosages, they concluded that only $40 \mathrm{~mW} / \mathrm{cm}^{2}$ was needed to reduce MNV infectivity by 2 logs, while this result was achieved beyond $180 \mathrm{~mW} / \mathrm{cm}^{2}$ for HAV [62].

Pulsed UV light has been reported to be more effective than conventional (continuous) UV light, inducing a more rapid inactivation of infectious agents. One 2-s treatment (6 pulses) can result in a 5-log decrease in the viral load for both MNV and HAV. Effectiveness is reduced in the presence of organic matter (fetal bovine serum) [61]. The effects of UV inactivation have been observed at the protein and RNA levels. It has been shown that UV disrupts the MNV-1 structure and degrades both viral protein and RNA [65].

\section{Heavy Metal-Impregnated Surfaces}

Certain heavy metals have been shown to have intrinsic antimicrobial effects. The most known include copper and gold. The effect of copper and copper alloy surfaces has been extensively investigated [66, 67]. Studies have shown a rapid inactivation of bacterial, fungal, and viral pathogens on copper and copper alloy surfaces, and these have led to clinical trials and real strategies for reduction of the microbial burden in some health settings $[68,69]$. Reports on enteric viruses have focused on noroviruses. MNV has been rapidly inactivated on copper and copper alloys containing over $60 \%$ of copper in both simulated wet fomite and dry touch contamination, while no reduction of infectivity has been observed on stainless steel. MNV is completely inactivated within $30 \mathrm{~min}$ on copper. The highest rate of inactivation occurs upon immediate contact and is proportional to the copper content of alloys. It has also been shown that $\mathrm{Cu}^{2+}$ and $\mathrm{Cu}^{+}$ions but not superoxide and hydroxyl radicals are the primary effectors of toxicity, and the targets are both viral capsid and RNA $[70,71]$. Similar findings have also been reported for human norovirus [72].

\section{Inactivation of Enteric Viruses on Fomites: Chemical Disinfectants}

Disinfectants are commonly used for virus inactivation, especially in the health care settings and the food industry, to prevent outbreaks due to enteric viruses.

The most popular disinfectants are ethanol, peroxyacids, chlorine, and quaternary ammonium. Laboratory or field investigations have evaluated the efficacy of these disinfectants for the inactivation of enteric viruses $[5,73]$. However, most of these studies have focused on human norovirus and cultivable surrogates as enteric virus models because human norovirus combines many of the epidemiological characteristics of enteric viruses [74].

MNV and FCV are to date the most common surrogates and the latter is still considered the gold standard by the US Environmental Protection Agency for evaluating the antinoroviral activity of new products. However, the use of multiple surrogate viruses rather than one is more judicious and recommended to obtain more reliable information on the effectiveness of disinfectants and this has been well documented in some studies [73, 75]. Indeed, differences in the sensitivity of the surrogates to experimental conditions and inactivation treatments have been reported. Some studies have shown that $\mathrm{MNV}$ is more susceptible to alcohols than FCV, whereas FCV is more susceptible to chlorine [76, 77]. In a systematic meta-analysis, Hoelzer et al. [73] showed that HAV and MNV were significantly more resistant to disinfection than FCV, even if the differences in viral titer reduction appeared to be modest (i.e., $1.5 \log$ PFU) [73].

Other studies have compared the efficacy of $3 \mathrm{com}$ monly used active agents (ethanol, chlorine, and quaternary ammonium) at different concentrations against 2 human norovirus strains and 2 surrogates (MNV and FCV). Data from these studies revealed a complete or relative lack of efficacy of quaternary ammonium against all of the viruses tested $[76,78,79]$. In another study FCV applied on a surface, but not in suspension, was effectively inactivated by a quaternary ammonium-based disinfectant, while CVB4, an enterovirus, was resistant [80]. Ethanol has shown minimal efficacy against human norovirus and FCV, but it is active against MNV, with a clear dose-dependent impact [76, 81-83]. Very high concentrations of hypochlorite ( $\geq 500 \mathrm{ppm}$ ) are necessary to inactivate human norovirus and MNV; FCV has been shown to be more susceptible to hypochlorite than human noroviruses $[76,79,81]$. 
Chlorine dioxide $\left(\mathrm{ClO}_{2}\right)$ represents a strong alternative to chlorine, with an increased ability to reduce or inactivate enteric viruses in the environment. $\mathrm{ClO}_{2}$ is very attractive compared to chlorine because it has been shown to be less affected by $\mathrm{pH}$ conditions than chlorine and very effective even at low concentrations $[84,85]$. Indeed, several studies have shown that the disinfection efficacy of $\mathrm{ClO}_{2}$ is higher than that of chlorine when tested on enteric viruses, including human rotavirus, enteric adenoviruses, caliciviruses, and enteroviruses [84-86]. However, commonly active doses of chlorine dioxide against these viruses have been shown to have some, albeit limited, activity against human norovirus $[87,88]$.

Taken together, all of these studies have highlighted the fact that human noroviruses are much less sensitive to commonly used disinfectants than surrogate viruses, and one might pay attention to and integrate several parameters when extrapolating data between surrogate viruses and human noroviruses.

Different peroxyacids, including peracetic, perpropionic, perlactic, and percitric, have been assessed for norovirus inactivation on stainless steel and polyvinyl chloride surfaces. Peracetic acid and perpropionic acid have been found to be the most effective. Exposure to a solution at $50 \mathrm{mg} / \mathrm{mL}$ for $5 \mathrm{~min}$ resulted in a $3-\log$ reduction of the viral titer in all of the conditions tested [89]. Interestingly, peracetic acid airborne disinfectant was reported by our team to be very efficient in inactivating poliovirus applied on stainless steel carriers [90].

\section{Conclusion}

Enteric viruses represent an important public health issue both in developed and in developing countries. These nonenveloped viruses have shown a high level of resistance in the environment. They can survive for a long time on animate and inanimate surfaces and be easily transferred to hands when hygiene measures are lacking. The role of fomites has been shown in the transmission of these viruses and the occurrence of outbreaks, especially in closed environments. Several factors impact the survival of viruses on fomites, and detailed experimental studies comparing all of the main enteric viruses are scarce. The implication of this strong resistance is the implementation of adequate disinfection strategies in health care centers and the food industry. Chemical disinfection is currently the most used in these settings, and great differences have been shown in the effects of various compounds on enteric viruses.

\section{References}

1 Kapusinszky B, Minor P, Delwart E: Nearly constant shedding of diverse enteric viruses by two healthy infants. J Clin Microbiol 2012; 50:3427-3434.

2 Wilhelmi I, Roman E, Sánchez-Fauquier A: Viruses causing gastroenteritis. Clin Microbiol Infect 2003;9:247-262.

3 Clark B, McKendrick M: A review of viral gastroenteritis. Curr Opin Infect Dis 2004;17: 461-469.

4 Lopman BA, Reacher MH, Van Duijnhoven Y, Hanon F-X, Brown D, Koopmans M: Viral gastroenteritis outbreaks in Europe, 19952000. Emerg Infect Dis 2003;9:90-96.

5 Rzezutka A, Cook N: Survival of human enteric viruses in the environment and food. FEMS Microbiol Rev 2004;28:441-453.

6 Lopman BA, Adak GK, Reacher MH, Brown DWG: Two epidemiologic patterns of norovirus outbreaks: surveillance in England and Wales, 1992-2000. Emerg Infect Dis 2003;9: 71-77.

7 Boone SA, Gerba CP: Significance of fomites in the spread of respiratory and enteric viral disease. Appl Environ Microbiol 2007;73: 1687-1696.

Resistance of Enteric Viruses on Fomites
8 Barker J, Jones MV: The potential spread of infection caused by aerosol contamination of surfaces after flushing a domestic toilet. J Appl Microbiol 2005;99:339-347.

9 Barker J, Vipond IB, Bloomfield SF: Effects of cleaning and disinfection in reducing the spread of Norovirus contamination via environmental surfaces. J Hosp Infect 2004;58: 42-49.

10 Gallimore CI, Taylor C, Gennery AR, Cant AJ, Galloway A, Xerry J, et al: Contamination of the hospital environment with gastroenteric viruses: comparison of two pediatric wards over a winter season. J Clin Microbiol 2008; 46:3112-3115.

11 Kramer A, Schwebke I, Kampf G: How long do nosocomial pathogens persist on inanimate surfaces? A systematic review. BMC Infect Dis 2006;6:130.

12 Abad FX, Pintó RM, Bosch A: Survival of enteric viruses on environmental fomites. Appl Environ Microbiol 1994;60:3704-3710.

13 Sattar SA, Lloyd-Evans N, Springthorpe VS, Nair RC: Institutional outbreaks of rotavirus diarrhoea: potential role of fomites and environmental surfaces as vehicles for virus transmission. J Hyg (Lond) 1986;96:277-289.
14 Abad FX, Villena C, Guix S, Caballero S, Pintó RM, Bosch A: Potential role of fomites in the vehicular transmission of human astroviruses. Appl Environ Microbiol 2001;67:3904-3907.

15 Mbithi JN, Springthorpe VS, Sattar SA: Effect of relative humidity and air temperature on survival of hepatitis A virus on environmental surfaces. Appl Environ Microbiol 1991;57: 1394-1399.

16 Tang JW: The effect of environmental parameters on the survival of airborne infectious agents. J R Soc Interface 2009;6:S737-S746.

17 Ansari SA, Springthorpe VS, Sattar SA: Survival and vehicular spread of human rotaviruses: possible relation to seasonality of outbreaks. Rev Infect Dis 1991;13:448-461.

18 Colas de la Noue A, Estienney M, Aho S, Perrier-Cornet J-M, de Rougemont A, Pothier P, et al: Absolute humidity influences the seasonal persistence and infectivity of human norovirus. Appl Environ Microbiol 2014;80: 7196-7205.

19 Nguyen JL, Schwartz J, Dockery DW: The relationship between indoor and outdoor temperature, apparent temperature, relative humidity, and absolute humidity. Indoor Air 2014;24:103-112. 
20 Wilde J, Van R, Pickering L, Eiden J, Yolken $\mathrm{R}$ : Detection of rotaviruses in the day care environment by reverse transcriptase polymerase chain reaction. J Infect Dis 1992;166: 507-511.

21 Butz AM, Fosarelli P, Dick J, Cusack T, Yolken R: Prevalence of rotavirus on highrisk fomites in day-care facilities. Pediatrics 1993;92:202-205.

22 Soule H, Genoulaz O, Gratacap-Cavallier B, Mallaret MR, Morand P, François P, et al: Monitoring rotavirus environmental contamination in a pediatric unit using polymerase chain reaction. Infect Control Hosp Epidemiol 1999;20:432-434.

23 Gallimore CI, Taylor C, Gennery AR, Cant AJ, Galloway A, Iturriza-Gomara M, et al: Environmental monitoring for gastroenteric viruses in a pediatric primary immunodeficiency unit. J Clin Microbiol 2006;44:395-399.

24 Ganime AC, Carvalho-Costa FA, Mendonça MCL, Vieira CB, Santos M, Costa Filho R, et al: Group A rotavirus detection on environmental surfaces in a hospital intensive care unit. Am J Infect Control 2012;40:544-547.

25 Rogers M, Weinstock DM, Eagan J, Kiehn T, Armstrong D, Sepkowitz KA: Rotavirus outbreak on a pediatric oncology floor: possible association with toys. Am J Infect Control 2000;28:378-380.

26 Green J, Wright PA, Gallimore CI, Mitchell O, Morgan-Capner P, Brown DW: The role of environmental contamination with small round structured viruses in a hospital outbreak investigated by reverse-transcriptase polymerase chain reaction assay. J Hosp Infect 1998;39:39-45.

27 Barker J, Stevens D, Bloomfield SF: Spread and prevention of some common viral infections in community facilities and domestic homes. J Appl Microbiol 2001;91:7-21.

$28 \mathrm{Wu}$ HM, Fornek M, Schwab KJ, Chapin AR, Gibson K, Schwab E, et al: A norovirus outbreak at a long-term-care facility: the role of environmental surface contamination. Infect Control Hosp Epidemiol 2005;26:802-810.

29 Repp KK, Keene WE: A point-source norovirus outbreak caused by exposure to fomites. J Infect Dis 2012;205:1639-1641.

30 Nenonen NP, Hannoun C, Svensson L, Torén $\mathrm{K}$, Andersson L-M, Westin J, et al: Norovirus GII.4 detection in environmental samples from patient rooms during nosocomial outbreaks. J Clin Microbiol 2014;52:2352-2358.

31 D'Arcy N, Cloutman-Green E, Klein N, Spratt DA: Environmental viral contamination in a pediatric hospital outpatient waiting area: implications for infection control. Am J Infect Control 2014;42:856-860.

32 Pankhurst L, Cloutman-Green E, Canales M, D'Arcy N, Hartley JC: Routine monitoring of adenovirus and norovirus within the health care environment. Am J Infect Control 2014; 42:1229-1232.
33 Ganime AC, Carvalho-Costa FA, Santos M, Costa Filho R, Leite JPG, Miagostovich MP: Viability of human adenovirus from hospital fomites. J Med Virol 2014;86:2065-2069.

34 Gallimore CI, Taylor C, Gennery AR, Cant AJ, Galloway A, Lewis D, et al: Use of a heminested reverse transcriptase PCR assay for detection of astrovirus in environmental swabs from an outbreak of gastroenteritis in a pediatric primary immunodeficiency unit. J Clin Microbiol 2005;43:3890-3894.

35 Sundkvist T, Hamilton GR, Hourihan BM, Hart IJ: Outbreak of hepatitis A spread by contaminated drinking glasses in a public house. Commun Dis Public Health 2000;3:60-62.

36 Julian TR, Tamayo FJ, Leckie JO, Boehm AB: Comparison of surface sampling methods for virus recovery from fomites. Appl Environ Microbiol 2011;77:6918-6925.

37 Park GW, Lee D, Treffiletti A, Hrsak M, Shugart J, Vinjé J: Evaluation of a new environmental sampling protocol for detection of human norovirus on inanimate surfaces. Appl Environ Microbiol 2015;81:5987-5992.

38 Rodríguez RA, Pepper IL, Gerba CP: Application of PCR-based methods to assess the infectivity of enteric viruses in environmental samples. Appl Environ Microbiol 2009;75: 297-307.

39 Ahmed SM, Hall AJ, Robinson AE, Verhoef L, Premkumar P, Parashar UD, et al: Global prevalence of norovirus in cases of gastroenteritis: a systematic review and meta-analysis. Lancet Infect Dis 2014;14:725-730.

40 Kim SJ, Si J, Lee JE, Ko G: Temperature and humidity influences on inactivation kinetics of enteric viruses on surfaces. Environ Sci Technol 2012;46:13303-13310.

41 Doultree JC, Druce JD, Birch CJ, Bowden DS, Marshall JA: Inactivation of feline calicivirus, a Norwalk virus surrogate. J Hosp Infect 1999; 41:51-57.

42 D'Souza DH, Sair A, Williams K, Papafragkou E, Jean J, Moore C, et al: Persistence of caliciviruses on environmental surfaces and their transfer to food. Int J Food Microbiol 2006; 108:84-91.

43 Bae J, Schwab KJ: Evaluation of murine norovirus, feline calicivirus, poliovirus, and MS2 as surrogates for human norovirus in a model of viral persistence in surface water and groundwater. Appl Environ Microbiol 2008; 74:477-484.

44 Kim A-N, Park SY, Bae S-C, Oh M-H, Ha S-D: Survival of norovirus surrogate on various food-contact surfaces. Food Environ Virol 2014;6:182-188.

45 Mormann S, Heißenberg C, Pfannebecker J, Becker B: Tenacity of human norovirus and the surrogates feline calicivirus and murine norovirus during long-term storage on common nonporous food contact surfaces. J Food Prot 2015;78:224-229.

46 Parashar UD, Hummelman EG, Bresee IS, Miller MA, Glass RI: Global illness and deaths caused by rotavirus disease in children. Emerg Infect Dis 2003;9:565-572.
47 Uhnoo I, Wadell G, Svensson L, Johansson ME: Importance of enteric adenoviruses 40 and 41 in acute gastroenteritis in infants and young children. J Clin Microbiol 1984;20: 365-372.

48 Verma H, Chitambar SD, Varanasi G: Identification and characterization of enteric adenoviruses in infants and children hospitalized for acute gastroenteritis. J Med Virol 2009;81: 60-64.

49 Bosch A, Pintó RM, Guix S: Human astroviruses. Clin Microbiol Rev 2014;27:10481074.

50 Aggarwal R, Goel A: Hepatitis A: epidemiology in resource-poor countries. Curr Opin Infect Dis 2015;28:488-496.

51 Rao DC, Ananda Babu M, Raghavendra A, Dhananjaya D, Kumar S, Maiya PP: Non-polio enteroviruses and their association with acute diarrhea in children in India. Infect Genet Evol 2013;17:153-161.

52 Hober D, Alidjinou EK: Enteroviral pathogenesis of type 1 diabetes: queries and answers. Curr Opin Infect Dis 2013;26:263-269.

53 Firquet S, Beaujard S, Lobert P-E, Sané F, Caloone D, Izard D, et al: Survival of enveloped and non-enveloped viruses on inanimate surfaces. Microbes Environ 2015;30: 140-144.

54 Nuanualsuwan S, Cliver DO: Inactivation of picornaviruses and caliciviruses. 2. Inactivation. Thai J Vet Med 2003;33:19-33.

55 Romero-Maraccini OC, Shisler JL, Nguyen TH: Solar and temperature treatments affect the ability of human rotavirus wa to bind to host cells and synthesize viral RNA. Appl Environ Microbiol 2015;81:4090-4097.

56 Kadoi K, Kadoi BK: Stability of feline caliciviruses in marine water maintained at different temperatures. New Microbiol 2001;24:17-21.

57 Duizer E, Bijkerk P, Rockx B, De Groot A, Twisk F, Koopmans M: Inactivation of caliciviruses. Appl Environ Microbiol 2004;70: 4538-4543.

58 Cannon JL, Papafragkou E, Park GW, Osborne J, Jaykus L-A, Vinjé J: Surrogates for the study of norovirus stability and inactivation in the environment: a comparison of murine norovirus and feline calicivirus. J Food Prot 2006;69:2761-2765.

59 Firquet S, Beaujard S, Lobert P-E, Sané F, Caloone D, Izard D, et al: Viruses contained in droplets applied on warmed surface are rapidly inactivated. Microbes Environ 2014; 29:408-412.

60 Fino VR, Kniel KE: UV light inactivation of hepatitis A virus, Aichi virus, and feline calicivirus on strawberries, green onions, and lettuce. J Food Prot 2008;71:908-913.

61 Jean J, Morales-Rayas R, Anoman M-N, Lamhoujeb S: Inactivation of hepatitis A virus and norovirus surrogate in suspension and on food-contact surfaces using pulsed UV light (pulsed light inactivation of food-borne viruses). Food Microbiol 2011;28:568-572. 
62 Park SY, Kim A-N, Lee K-H, Ha S-D: Ultraviolet-C efficacy against a norovirus surrogate and hepatitis A virus on a stainless steel surface. Int J Food Microbiol 2015;211:73-78.

63 Gerba CP, Gramos DM, Nwachuku N: Comparative inactivation of enteroviruses and adenovirus 2 by UV light. Appl Environ Microbiol 2002;68:5167-5169.

64 Lamont Y, Rzezutka A, Anderson JG, MacGregor SJ, Given MJ, Deppe C, et al: Pulsed UV-light inactivation of poliovirus and adenovirus. Lett Appl Microbiol 2007;45:564567.

65 Vimont A, Fliss I, Jean J: Efficacy and mechanisms of murine norovirus inhibition by pulsed-light technology. Appl Environ Microbiol 2015;81:2950-2957.

66 Wilks SA, Michels H, Keevil CW: The survival of Escherichia coli O157 on a range of metal surfaces. Int J Food Microbiol 2005;105: 445-454.

67 Warnes SL, Caves V, Keevil CW: Mechanism of copper surface toxicity in Escherichia coli O157:H7 and Salmonella involves immediate membrane depolarization followed by slower rate of DNA destruction which differs from that observed for Gram-positive bacteria. Environ Microbiol 2012;14:1730-1743.

68 Schmidt MG, Attaway HH, Sharpe PA, John J, Sepkowitz KA, Morgan A, et al: Sustained reduction of microbial burden on common hospital surfaces through introduction of copper. J Clin Microbiol 2012;50:2217-2223.

69 Salgado CD, Sepkowitz KA, John JF, Cantey JR, Attaway HH, Freeman KD, et al: Copper surfaces reduce the rate of healthcare-acquired infections in the intensive care unit. Infect Control Hosp Epidemiol 2013;34:479486.

70 Warnes SL, Keevil CW: Inactivation of norovirus on dry copper alloy surfaces. PLoS One 2013;8:e75017.
71 Warnes SL, Summersgill EN, Keevil CW: Inactivation of murine norovirus on a range of copper alloy surfaces is accompanied by loss of capsid integrity. Appl Environ Microbiol 2015;81:1085-1091.

72 Manuel CS, Moore MD, Jaykus LA: Destruction of the capsid and genome of GII.4 human norovirus occurs during exposure to metal alloys containing copper. Appl Environ Microbiol 2015;81:4940-4946.

73 Hoelzer K, Fanaselle W, Pouillot R, Van Doren JM, Dennis S: Virus inactivation on hard surfaces or in suspension by chemical disinfectants: systematic review and metaanalysis of norovirus surrogates. J Food Prot 2013;76:1006-1016.

74 Moore MD, Goulter RM, Jaykus L-A: Human norovirus as a foodborne pathogen: challenges and developments. Annu Rev Food Sci Technol 2015;6:411-433.

75 Hirneisen KA, Kniel KE: Comparing human norovirus surrogates: murine norovirus and Tulane virus. J Food Prot 2013;76:139-143.

76 Tung G, Macinga D, Arbogast J, Jaykus L-A: Efficacy of commonly used disinfectants for inactivation of human noroviruses and their surrogates. J Food Prot 2013;76:1210-1217.

77 Park GW, Barclay L, Macinga D, Charbonneau D, Pettigrew CA, Vinjé J: Comparative efficacy of seven hand sanitizers against murine norovirus, feline calicivirus, and GII.4 norovirus. J Food Prot 2010;73:2232-2238.

78 Abad FX, Pintó RM, Bosch A: Disinfection of human enteric viruses on fomites. FEMS Microbiol Lett 1997;156:107-111.

79 Girard M, Ngazoa S, Mattison K, Jean J: Attachment of noroviruses to stainless steel and their inactivation, using household disinfectants. J Food Prot 2010;73:400-404.

80 Thevenin T, Lobert PE, Hober D: Inactivation of coxsackievirus B4, feline calicivirus and herpes simplex virus type 1: unexpected virucidal effect of a disinfectant on a non-enveloped virus applied onto a surface. Intervirology 2013;56:224-230.
81 Belliot G, Lavaux A, Souihel D, Agnello D, Pothier P: Use of murine norovirus as a surrogate to evaluate resistance of human norovirus to disinfectants. Appl Environ Microbiol 2008;74:3315-3318.

82 Macinga DR, Sattar SA, Jaykus L-A, Arbogast JW: Improved inactivation of nonenveloped enteric viruses and their surrogates by a novel alcohol-based hand sanitizer. Appl Environ Microbiol 2008;74:5047-5052.

83 Magulski T, Paulmann D, Bischoff B, Becker B, Steinmann E, Steinmann J, et al: Inactivation of murine norovirus by chemical biocides on stainless steel. BMC Infect Dis 2009; 9:107.

84 Thurston-Enriquez JA, Haas CN, Jacangelo J, Gerba CP: Inactivation of enteric adenovirus and feline calicivirus by chlorine dioxide. Appl Environ Microbiol 2005;71:3100-3105.

85 Xue B, Jin M, Yang D, Guo X, Chen Z, Shen $Z$, et al: Effects of chlorine and chlorine dioxide on human rotavirus infectivity and genome stability. Water Res 2013;47:33293338.

86 Zoni R, Zanelli R, Riboldi E, Bigliardi L, Sansebastiano G: Investigation on virucidal activity of chlorine dioxide: experimental data on feline calicivirus, HAV and Coxsackie B5. J Prev Med Hyg 2007;48:91-95.

87 Nowak P, Topping JR, Fotheringham V, Gallimore CI, Gray JJ, Iturriza-Gómara M, et al: Measurement of the virolysis of human GII.4 norovirus in response to disinfectants and sanitisers. J Virol Methods 2011;174:7-11.

88 Kingsley DH, Vincent EM, Meade GK, Watson CL, Fan X: Inactivation of human norovirus using chemical sanitizers. Int J Food Microbiol 2014;171:94-99.

89 Vimont A, Fliss I, Jean J: Study of the virucidal potential of organic peroxyacids against norovirus on food-contact surfaces. Food Environ Virol 2015;7:49-57.

90 Thevenin T, Lobert P-E, Hober D: Inactivation of an enterovirus by airborne disinfectants. BMC Infect Dis 2013;13:177. 